\title{
THE ECONOMICS OF RECYCLING AS PREMISE OF CIRCULAR ECONOMY: FROM GOVERNMENTAL SUPPORT TO FUNCTIONAL MARKETS
}

\author{
Florina Bran' ${ }^{1}$, Ildiko Ioan ${ }^{1}$, Carmen Valentina Radulescu ${ }^{1}$ \\ ${ }^{1}$ The Bucharest University of Economic Studies, Piata Romana nr.6, Sector 1, \\ Bucharest, florinabran@yahoo.com, Romania
}

\begin{abstract}
Environment covers a number of stages within the material loop that allow industrial development and value creation. Holding the resource for a long while, concentrating some materials, decomposing others are processes that exceed the limits of industrial activity. A better use of materials is a mandatory requirement of sustainable development. Closed loops of material streams are the most common vision in this respect. Despite the innovative technological solutions, a functional market for major material streams is still struggling to emerge. Using a case study for one of the most dynamic waste streams - electric and electronic equipment (WEEE) - there are indicated critical factors that impact on the businesses of the WEEE value chain. A better understanding of how these factors influence the businesses of all involved players could bring important improvements in policy making toward a circular economy based on a functional market.
\end{abstract}

Keywords: sustainable development, recycling, circular economy, businesses, WEEE

\section{Introduction}

Sustainable development requires major changes in how humans are relating with their natural environment. Among these changes one of the most important one is regarding the transformation of materials because the dysfunctional pattern of how materials are transformed is the root cause for most of the environmental issues that fall in the resource exhaustion or pollution categories [1].

The understanding of the complex causality of these issues is advanced enough for becoming a fertile ground for developing technological solutions. The design of sustainable material flows was inspired by the natural model. Thus, the circular flow of materials, based on recycling of waste and continuous renewal of resources, served as model for many conceptual approaches that include, but are not limited to industrial ecology or symbiosis, cradle to cradle, eco-profit or circular economy [2].

The European policy supports the model of the circular economy that is envisioned as an economy in which the pattern of value added generation and preservation is different from the regular one. The circular economy requires changes throughout the value chains, including technical innovations, but especially business model innovations [3].

A particular focus of EU policy is on the most dynamic waste streams - the stream of electric and electronic equipment waste (WEEE or e-waste). For encouraging the recycling it was approved the WEEE directive based on the principle of extended producer responsibility (EPR). Nonetheless, WEEE management within EU continues to have many pitfalls including a significant amount of WEEE export along with the struggle of incumbent companies to withstand increasing costs. Based on an in-depth analysis of the WEEE recycling economics we are aiming to highlight some critical 
factors that should be considered for policy making in order to support the development of the circular economy on the solid bases provided by a functional market.

\section{Experimental: hypothesis development}

According to the current economic theory of value [4], the market value, usually expressed by the price, is given by the utility of the product or service, namely by how successful is the product or service in satisfying a necessity of its buyer. A first condition of the circular economy is that products or services involved in the recovery of materials from waste are demanded, being useful for others. For instance, a company that collects household waste should have a customer that buys its product, the waste that is collected. In the current setting, the household waste, as material, has no value, meaning that nobody buys it from the collector. Within the circular economy, the collected waste should be sold to a recycler that has the technology needed to recover the valuable materials. A condition for this is that the buyer should be able to provide the recovered material for a competitive price.

On its turn, price is the result of the interplay between supply and demand. Many materials are provided on the market through the exploitation of natural resources like ores, forests, fossil fuels etc. The recovered materials will compete with them on the market. Recovered materials should be competitive by having either lower prices or better quality than the ones obtained from the natural resources. It results that the costs of recovering materials from waste should be lower than the costs of obtaining materials from natural resources. For example, recycled paper should be cheaper than paper obtained from wood, metals recovered from scrap should be cheaper than metals obtained from processing ores and so on.

Our analysis will focus on WEEE. Despite some common features, this type of waste comprises many materials like plastic, glass and a wide range of metals and rare earths (more than forty substances). Recycling WEEE aims recovering especially metals, many of them being precious metals like gold, platinum or silver or rare compounds like palladium or europium.

For understanding the economics of this waste stream it should be considered some important characteristics of the current economic context. These include globalization that allows a freer movement of capital, goods, people, know-how etc. [5]. In this context, the price will depend on how cost could be lowered in a global setting, context in which there are huge gaps in the influence of factors that impact on costs. Burning plastic in open air has no cost in China or Ghana, while in Germany it will result either in a high liability or an expensive burning technology. Dismantling a remote control is much cheaper in India where the wages are far lower than in EU. Nevertheless, materials that are recovered in EU will compete with materials that are recovered in China or India. Consequently, WEEE tends to be recycled where the recovery of the valuable material is less costly. Avoiding the shipment of WEEE from EU to developing countries would be possible by:

Major cost reduction in EU through:

- Policy measures that ensure a more equitable distribution of costs among manufacturers, distributors, consumers, and end-of-life managers and

- Technological, managerial or business model innovation (that could be also supported by government);

- $\quad$ Restraining WEEE flows by regulations;

- $\quad$ Uniform environmental standards and wages in all countries. 
Some of these conditions are met today, but they should be further enhanced since the results are not yet indicative for a circular economy.

For more than a decade, in EU it is enforced the WEEE directive (2002/96/EC) having as goal the prevention, reuse, recycling and other forms of recovery of WEEE in order to reduce the disposal of waste. The main principle that underpins this directive is the extended producer responsibility (EPR) according to that producers are responsible for collecting and appropriate treatment of WEEE by financing these operations.

Nonetheless, the economics of WEEE recycling is revealing a dysfunctional market with contradictory symptoms like increasing amounts of collected WEEE and input shortages for large players. Downstream recyclers (shredders, separators, and secondary processors) point the finger on the large amount of collected WEEE that does not reach them, while upstream recyclers (especially collectors) are making choices at the edge of compliance, assuming the risk of liabilities for illegal exports.

Our hypothesis is that initially the WEEE processing capacity was not large enough to meet the needs of collectors and other upstream players (sorters, de-polluters, dismantlers) making room for international WEEE brokers who harnessed the opportunity of large amounts of collected WEEE and created strong bounds with collectors. For the demonstration, firstly we analyze the economics of WEEE recycling that will reveal the most important logical connections. Further, the reason is developed using industry and statistical data regarding WEEE collecting and treatment within EU.

\section{Results and discussions}

\section{Understanding the economics of WEEE recycling in EU}

The WEEE concept developed out of the need to handle a mounting stream of waste that on the one hand represented a major environmental threat by releasing harmful chemicals (mercury, lead, CFCs, PCB etc.) and on the other hand contain valuable metals (iron, copper, aluminum, zinc, lead, precious metals, including gold) the recovery of that was recognized as a possible solution for withstanding the increasing scarcity of that materials on the global market [6]. Thus, WEEE recycling has a twofold motivation: reducing pollution and avoiding the loss of valuable materials.

Within the regulatory framework that encouraged WEEE treatment it was also recognized the opportunity for reuse and refurbishment that became one of the most important revenue sources [7], [8], [9].

By its content of valuable metals, WEEE could be regarded as a complex ore. The volume of WEEE to be handled for recovering the metals is not exceeding volumes with that the mining industry is accustomed [9]. Nonetheless, WEEE is a heterogeneous mass that is not readily available in large quantities.

WEEE comprises ten product categories and for each of them there are established recycling and recovery rates, but also depollution requirements. The ten categories of products are: large household appliances, automatic dispensers, IT and telecommunication equipment, consumer equipment, small household appliances, lighting equipment, electrical and electronic tools, toys, leisure and sports equipment, monitoring and control instruments, lighting equipment, and medical devices.

The WEEE policy is considered the main driver for the development of businesses in this sector [7], [10], [9]. This means that in the absence of this policy WEEE recycling is not an attractive business. This is because some costs are too large to be covered by the revenues that could be obtained from selling products or providing services [11]. Thus the existence of EU policy regarding WEEE is an important premise of the circular economy. 


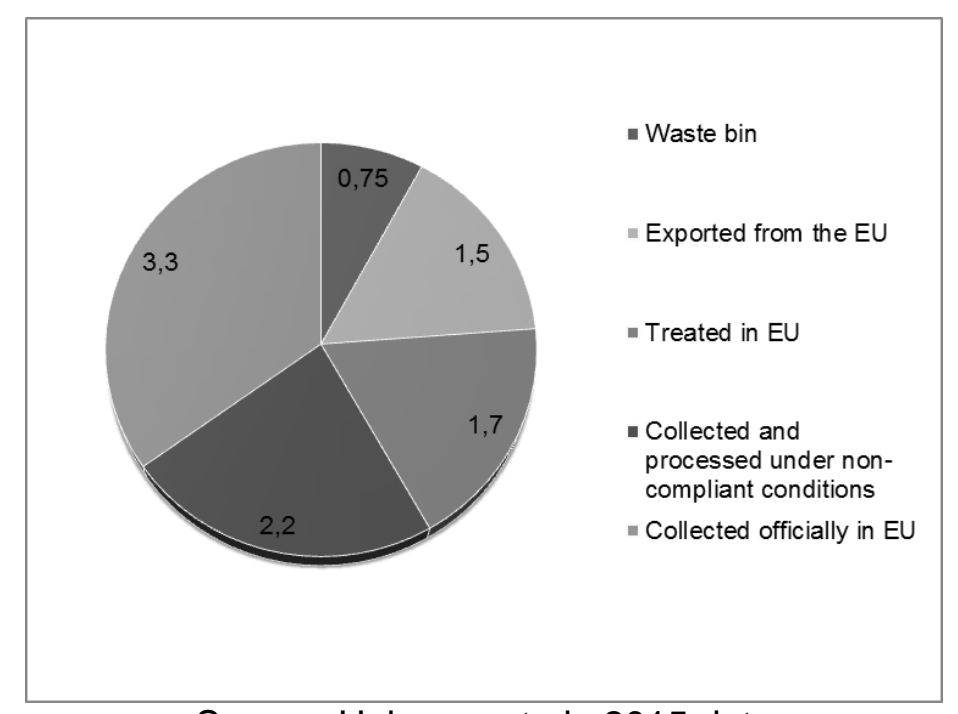

Source: Huisman et al., 2015 data

Figure 1 Structure of WEEE stream (million tons)

The European WEEE stream is accounting for 10 million tons per year and is the fastest growing category of municipal waste with an annual growth rate of $4-5 \%$ [12], [13], [9]. As long as structure is regarded, beside the one based on the categories established by the WEEE directive, the economic analysis also considers aspects regarding the pathways followed by WEEE. Figure 1 presents the structure from this point of view.

Recovering materials from WEEE should be underpinned by a solid economic motivation. This motivation can be derived by estimating the amounts of materials that could be recovered and the market value of those materials. Such an assessment was conducted by considering fourteen categories of products [14]. The results, framed in two scenarios, showed that the economic potential of WEEE is large enough to be addressed seriously by targeted policy measures. The total value of materials that could be recovered ranges between 2.15 and 3.67 billion euro. Out of this, gold is responsible for more than half, while in case of low value materials the economic potential becomes attractive only if large amounts are made available for transactions. The sensitivity analysis showed that the most influential factors that prevent the materialization of the economic potential are the market price variation for many metals, including gold and the reduced purity, especially in case of smart phones and tablets.

WEEE recycling is not a single activity and usually the whole range of activities is not performed by a single company. Further, beside companies there are other actors that could have decisive influence for the businesses like NGOs, policy makers, and academics. As it already was stressed, the lack of regulatory framework prevents any WEEE recycling business to occur.

For this purpose, the value chain approach could be applied. The WEEE recycling value chains comprises the following activities: collection, transportation, sorting, depollution and dismantling, shredding and separation, and secondary processing [9]. Costs are influenced by many factors. The latest stages depend greatly on the feed-in with WEEE, and the whole chain relies on collecting. Some of the costs are currently supported by manufacturers, importers, and distributors, in accordance with EPR requirements. 
Some studies framed their analysis on a certain stream of WEEE. In the economics of cell phone recycling the only profitable option is reuse. The gold content of this equipment is the most important factor that influences the profitability of recycling [8].

\section{WEEE collecting and treatment in EU: volumes and capacities}

The economic analysis revealed that WEEE collecting is generating high costs. A large part of these costs is represented by fixed costs, indicating that an appropriate infrastructure could have a significant contribution for reducing costs. Despite this difficulty, many of EU most Member States (21 out of 28) report a collected WEEE amount that meets the policy target of 4 kilograms per capita (figure 2).

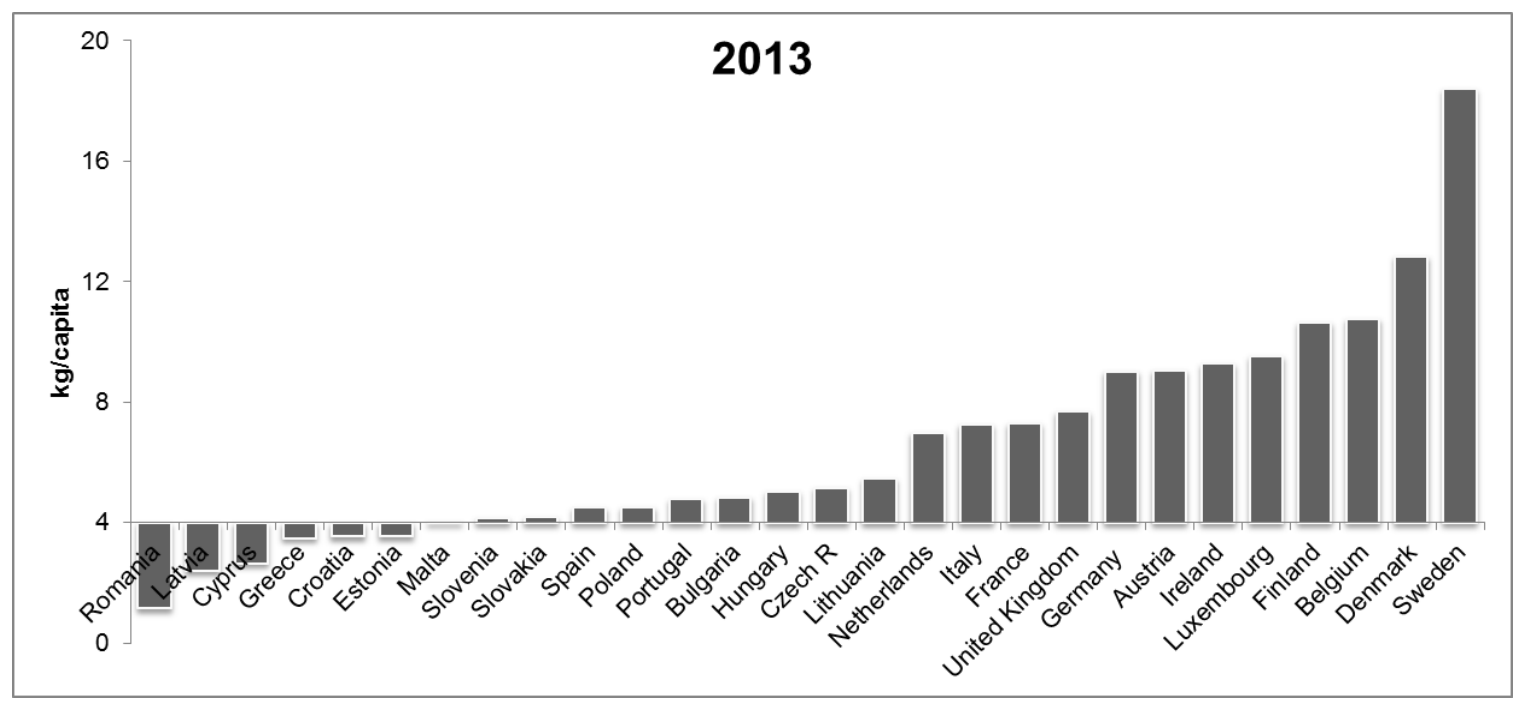

Source: Eurostat data

Figure 2 Collected WEEE against the target of $4 \mathrm{~kg} /$ capita

The means of collecting waste are very different from one Member States to another and there are a large number of enterprises that assumed this role. There is a quite strong relation between the amount collected and costs. It was calculated that for large quantities the collection cost is of 100 euro per ton, while in case of small quantities cost is over 500 euro per ton [9].

As long as treatment is regarded statistical data capture two streams: reuse (equipment or components) and recovery of materials.

Many EEE could be further used with relatively low cost refurbishment (UEEE), while some of the components like compressors for temperature exchange equipment, memory, hard disk and other small IT components are scavenged at collection or sorting points. The amount that is reported as reused reached almost 85 thousand tons in 2011, but after this tipping point the annual quantities decreased (figure 3). This represents a very small fraction from the total collected WEEE, but the estimated value is 200-500 million euro. Nonetheless, some of the upstream WEEE players are strongly dependent on the revenue obtained from this source [15]. 


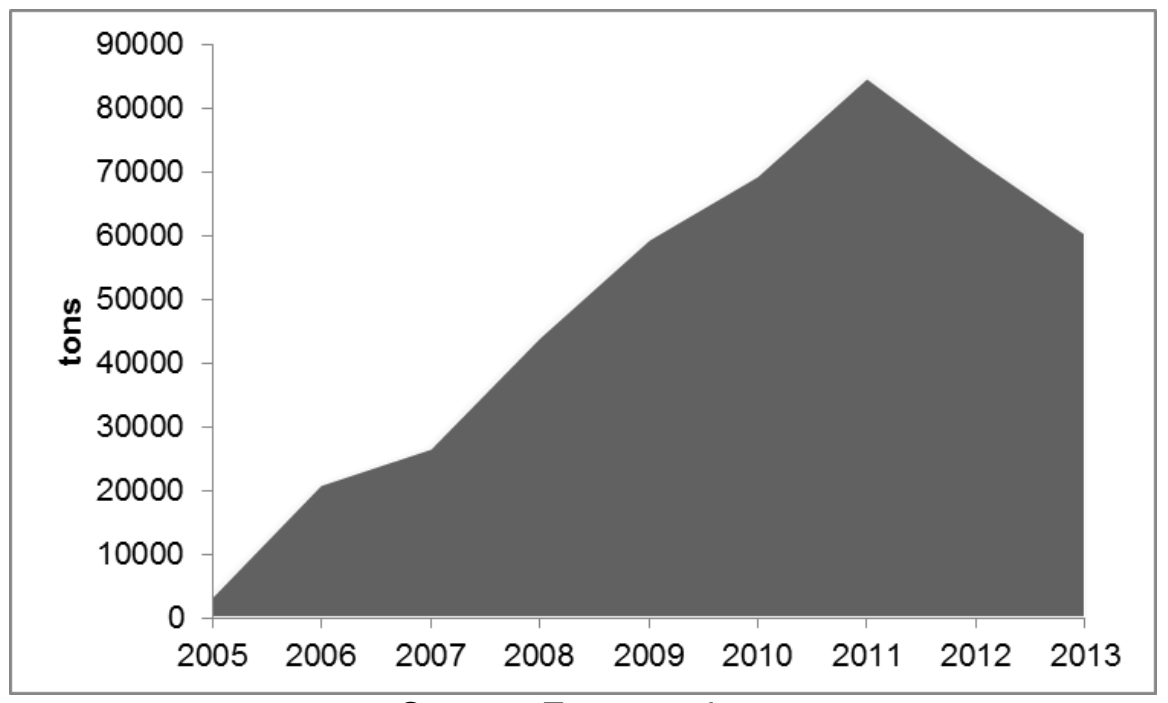

Source: Eurostat data

Figure 3 Variation of reused WEEE quantity in EU

The recovery of materials necessitates further processing, adding more costs, while the resulted product has smaller value. Thus the profit margin is narrowing down toward the downstream WEEE players like shredders, separators, and secondary processors. The business strategies for these players are specialization (diseconomies of scope) and expanding the processing capacity (economies of scale).

The capacity of WEEE processing is not monitored as such. Fact is, many major players, like Stena Technoworld, Kuusakoski, Sims, do not recycle only WEEE, while some secondary processors are often also metal smelters. In a report for EU, it is mentioned that EU15 states are likely to have or are about to invest in the necessary capacity to process the WEEE resulted by the implementation of the WEEE directive [16].

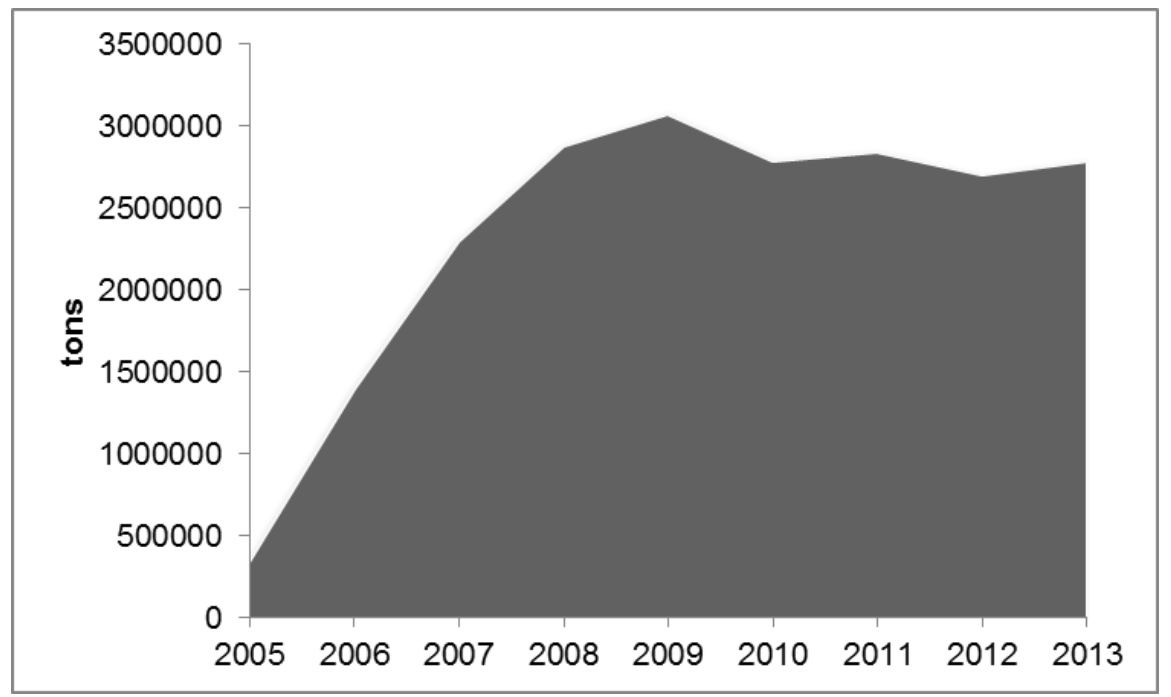

Source: Eurostat data

Figure 4 Variation of material recovery from WEEE in EU

The largest companies, Boliden (Sweden), Aurubis Group (Germany), Umicore (Belgium) have facilities that could process up to 350 thousand tons of WEEE per year. Investments in WEEE treatment facilities were also made in Eastern Europe. Thus in Romania it was established the largest WEEE facility for this region operated by 
Greenweee International Romania. Its capacity is of 50 thousand tons, having lines for each category of WEEE. Great capacities are also in place in UK - around 600 thousand tons.

Data regarding the amount of WEEE that is treated for the recovery of materials reveal a steep growth until 2009 , followed by an almost flat evolution, that could be interpreted as a signal for the end of WEEE recycling investment (figure 4).

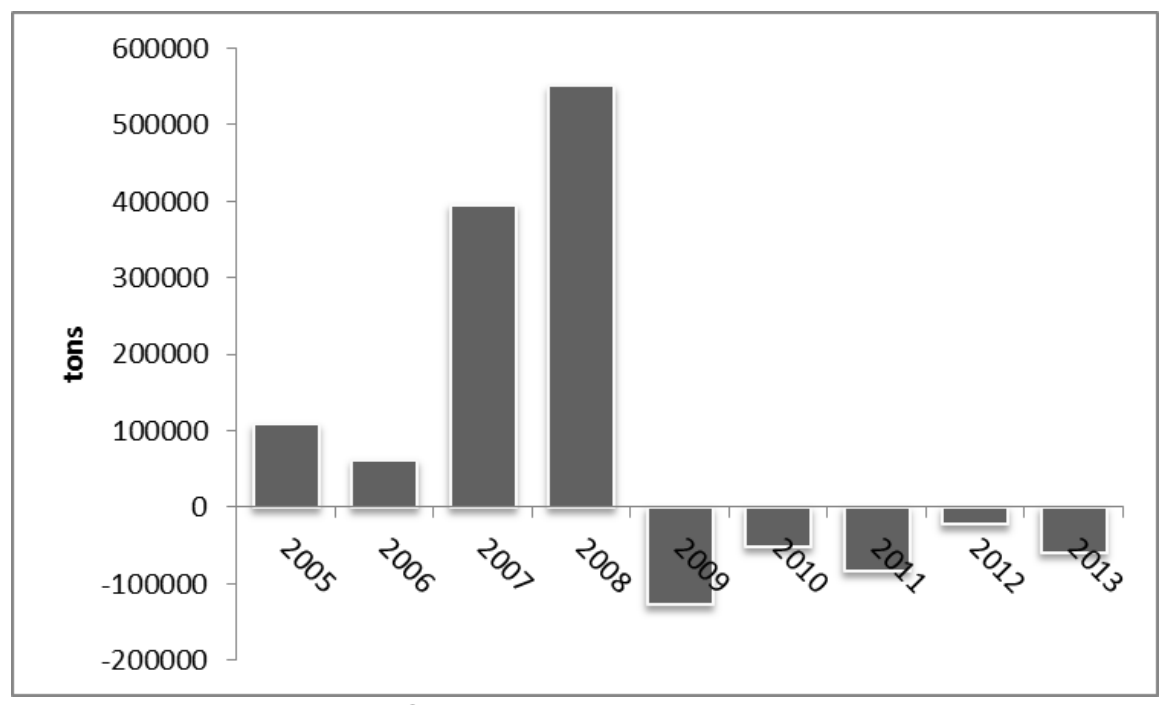

Source: Eurostat data

Figure 5 The difference between WEEE amounts collected and treated in EU

An interesting insight could be captured by comparing the collected and treated amounts in EU (figure 5). Thus, until 2009 the treatment capacity was not able to handle the collected WEEE. Afterward the amount that is treated is beyond the quantity that is collected. This could indicate a competition for the "raw material" represented by the collected WEEE. Meanwhile, it could be also inferred that downstream players faced increasing costs due to low rate of capacity usage. The largest differences were recorded for Italy, where the amount of collected WEEE was exceeded by the treated WEEE with 100 thousand tons.

\section{Conclusions}

Circular economy is an economy in that products are used for longer periods, materials are recovered from wastes, and energy is used efficiently [3]. Out of these characteristics our analysis focused on the need of recovering materials from wastes, in particular from WEEE.

Reaching a circular economy is possible only if the activities that are needed for recovering materials from wastes are an opportunity of value added that could be harnessed using existing or forward looking business models. Activities such as collecting, transportation, sorting, de-polluting, shredding, separation, secondary processing, brokering, refurbishment, reuse etc. should allow the development of businesses, meaning that the market value of the product or service that they deliver should be larger than the costs of performing the activities. Shortly, two conditions should be met: good for business and good for environment.

The economic analysis of how the WEEE stream is managed in the EU revealed that there are a number of critical aspects for the development of a circular economy. These include, but are not limited to: 
Cost of collection - it could be reduced by collaborative agreements and by the establishment of a collecting infrastructure that is convenient for the consumer; - $\quad$ Revenues generated by reuse of equipment or components - it could and should be captured by sorting with the involvement of social enterprises;

- $\quad$ Capacity utilization - shredding and separation and secondary processing could be profitable only by operating large capacities and using most of it (economies of scale);

- $\quad$ Suitable recovery technology that ensures high purity materials to be obtained; even if this condition is provided there are manufacturers that are reluctant in using recycled materials;

- $\quad$ Specialization could increase profitability, especially for downstream players (diseconomies of scope);

- $\quad$ Manufacturers could reduce costs for de-pollution and dismantling by providing information and by improving product design.

One of the greatest challenges of the European WEEE management is the "leaching" of great amounts toward developing countries. The industry's major players claim for a better governance, especially since they invested heavily in capacity development.

The statistic data, that is claimed to count only for one third of the total amount of WEEE, supports our hypothesis regarding the lack of processing capacity in the initial stage of the WEEE directive implementation. It also indicates that collected WEEE is a valuable asset for which competition has a global scale. The economics highlighted that one of the most important costs in this industry is born in the collecting stage.

Data regarding WEEE treatment capacity is not readily available, despite the fact that one critical factor is its rate of usage. It might be possible that in EU there is still a shortage of processing capacity, at least compared with the annual amount of 10 million tons (only 3.6 million tons are treated in EU). More likely is however that the offer of downstream processors is less attractive for upstream collectors and sorters than the one coming from brokers that manage overseas shipments.

Further studies should consider a thorough analysis of WEEE collection infrastructure and treatment capacities, the means of procurement for the businesses that operate the largest facilities, and innovative business models that better capture value from reuse and refurbishment.

\section{References}

[1]. Bran, F., Ioan, I. (2013). Terra - casa vieții, Bucharest: Universitară Publishing.

[2]. Bran, F., loan, I., Radulescu, C. V. (2014). Economic pathways towards a more sustainable material flow. Case study: product service systems. In Proceedings of the International Management Conference, Vol. 8, No. 1, pp. 358-369. Faculty of Management, Academy of Economic Studies, Bucharest, Romania.

[3]. EC. (2014). Towards a circular economy: a zero waste programme for Europe. $\mathrm{COM} / 2014 / 0398$ final.

[4]. Bran, P. (2001). Economica valorii, Bucharest: ASE Publishing.

[5]. Bran, F., Manea, G., Ioan, I., Radulescu, C. V. (2012). Globalizarea. Manifestari si reactii. Bucharest:Economica Publishing.

[6]. Ciocoiu, N., Burcea, S., Tartiu, V. (2010). The WEEE management system in Romania. Dimension, strengths and weaknesses. Theoretical and Empirical Researches in Urban Management, (15), 5-22.

[7]. Namias, J. (2013). The future of electronic waste recycling in the United States: Obstacles and domestic solutions. Doctoral dissertation, Columbia University, US.

[8]. Geyer, R., Blass, V. D. (2010). The economics of cell phone reuse and recycling. The International Journal of Advanced Manufacturing Technology,47(5-8), 515-525. 
[9]. Bohr, P. (2007). The economics of electronics recycling: new approaches to extended producer responsibility., Doctorat Thesis, Technischen Universität Berlin, Germany.

[10]. Walther, G., Steinborn, J., Spengler, T. S., Luger, T., Herrmann, C. (2010). Implementation of the WEEE-directive-economic effects and improvement potentials for reuse and recycling in Germany.The International Journal of Advanced Manufacturing Technology,47(5-8), 461-474.

[11]. Păcesilă, M., Ciocoiu, C. N., Colesca, S. E., Burcea, Ş. G. (2010) An Overview Of Cost Benefit Analysis For Weee Recycling Projects. Proceedings of the 9th international management conference Management and Innovation For Competitive Advantage, November 5th-6th, 2015, Bucharest.

[12]. Huisman, J., Botezatu, I., Herreras, L., Liddane, M., Hintsa, J., Luda di Cortemiglia, V., Leroy, P., Vermeersch, E., Mohanty, S., van den Brink, S., Ghenciu, B., Dimitrova, D., Nash, E., Shryane, T., Wieting, M., Kehoe, J., Baldé, C.P., Magalini, F., Zanasi, A., Ruini, F., and Bonzio, A. (2015). Countering WEEE Illegal Trade (CWIT) Summary Report, Market Assessment, Legal Analysis, Crime Analysis and Recommendations Roadmap, August 30, Lyon, France.

[13]. Ciocoiu, N.C., Dobrea, C.R. (2008). The Digital Economy and the Evolution of Waste Electrical and Electronic Equipment in European Union, IBIMA Conference, vol.4, 8-12.

[14]. Cucchiella, F., D’Adamo, I., Koh, S. L., Rosa, P. (2015). Recycling of WEEEs: An economic assessment of present and future e-waste streams. Renewable and Sustainable Energy Reviews,51, 263-272.

[15]. Li, D. (2015). The future of green investment in wasted electrical and electronic equipment recycling sector in China. Bachelor thesis, International Business School of Business Administration, JAMK, Finland.

[16]. Huisman, J., Delgado, C., Magalini, F., Kuehr, R., Maurer, C., Artim, E., Szlezak, J., Ogilvie, S., Poll, J., Stevels, A. (2008). 2008 Review of Directive 2002/96 on Waste Electrical and Electronic Equipment (WEEE). Final report. 